\title{
MUDAS DE LARANJEIRA 'VALÊNCIA' SOBRE DOIS PORTA-ENXERTOS E SOB DIFERENTES MANEJOS DE ADUBAÇÃ̃ ${ }^{1}$
}

\author{
EDUARDO AUGUSTO GIRARDI², FRANCISCO DE ASSIS ALVES MOURÃO FILHO ${ }^{3}$, \\ ANDRÉ SIQUEIRA RODRIGUES ALVES ${ }^{4}$
}

RESUMO - O manejo da adubação é uma das principais práticas culturais para a produção de mudas cítricas em cultivo protegido. Avaliou-se o efeito de seis tipos de manejo das adubações comercialmente recomendadas na produção de mudas de laranjeira 'Valência' [Citrus sinensis (L.) Osbeck] enxertada sobre os porta-enxertos limoeiro 'Cravo' (Citrus limonia Osbeck) e citrumeleiro 'Swingle' [Citrus paradisi Macf. $\mathrm{x}$ Poncirus trifoliata (L.) Raf.]. As avaliações foram conduzidas a partir da transplantação dos porta-enxertos até 180 dias após a enxertia, em viveiro empresarial, em Conchal-SP. Os manejos corresponderam a duas soluções de fertilizantes solúveis aplicadas isoladamente, soluções de fertilizante solúveis associadas a fertilizante de liberação controlada e aplicação exclusiva de fertilizante de liberação controlada. O delineamento experimental adotado foi o fatorial 2 x 6 (porta-enxerto x manejo da adubação), em blocos casualizados, com três repetições e 12 mudas na parcela. O limoeiro 'Cravo' induziu maior crescimento ao enxerto. O crescimento vegetativo das mudas foi similar após o uso de fertilizantes solúveis ou de liberação controlada, apesar da grande variação de quantidades totais de nutrientes fornecidas às plantas. Desta forma, o viveirista poderá optar pelo manejo mais econômico ou prático, conforme as condições locais.

Termos para indexação: Citrus spp., propagação, cultivo protegido, substrato, fertilizantes.

\section{'VALENCIA' SWEET ORANGE NURSERY TREES ON TWO ROOTSTOCKS UNDER DIFFERENT FERTILIZER MANAGEMENTS}

\begin{abstract}
The fertilizer program is a major practice for screened citrus nursery tree production. The effect of six fertilizer programs commercially recommended was evaluated on the production of 'Valencia' sweet orange [Citrus sinensis (L.) Osbeck] nursery trees budded on rootstocks 'Rangpur' lime (Citrus limonia Osbeck) and 'Swingle' citrumelo [Citrus paradisi Macf. x Poncirus trifoliata (L.) Raf.]. Experimental work was carried out from rootstock transplant until 180 days after budding, in a citrus nursery in Conchal, SP, Brazil. Fertilizer managements consisted of two soluble fertilizers solutions applied isolated, soluble fertilizers associated with control release fertilizer and control release fertilizer alone. Experimental design was factorial $2 \times 6$ (rootstock $\mathrm{x}$ fertilizer program) in randomized blocks, with three replicates and 12 plants in the unit. 'Rangpur' lime induced higher vigor to the scion. Plant growth was similar among fertilizer managements, even though nutrient amounts applied varied significantly. Therefore, nurserymen can choose the most practical or economic management depending on local conditions.
\end{abstract}

Index terms: Citrus spp., propagation, screen house, potting mix, fertilizing.

\footnotetext{
'(Trabalho 073-09). Recebido em: 31-03-2009. Aceito para publicação em: 06-04-2010.

${ }^{2}$ Engenheiro Agrônomo, Dr, Estação Experimental de Citricultura de Bebedouro, Rod. Brigadeiro Faria Lima, km 384, Caixa Postal 74, CEP: 14700-970 Bebedouro-SP. eagirardi@yahoo.com.br. Primeiro autor é bolsista de pós-doutorado da FAPESP.

${ }^{3}$ Engenheiro Agrônomo, PhD, Professor Associado do Departamento de Produção Vegetal, Escola Superior de Agricultura "Luiz de Queiroz", Universidade de São Paulo, Av. Pádua Dias, 11, Caixa Postal 9, CEP: 13418-900 Piracicaba-SP. famourao@esalq.usp.br (*) Autor correspondente. Tel.: (019) 3429-4190. Segundo autor é bolsista de produtividade em pesquisa do CNPq.

${ }^{4}$ Engenheiro Agrônomo, MSc, Casa do Café, Rua Água Santa, 331, CEP: 14406-668 Franca-SP. asralves@yahoo.com.br.
} 


\section{INTRODUÇÃO}

Em substratos inertes, a adubação deve fornecer todos os nutrientes necessários ao crescimento das mudas de citros (MILNER, 2002), de modo que a fertilização com $\mathrm{N}, \mathrm{Ca}, \mathrm{P}, \mathrm{K}, \mathrm{B}$ e $\mathrm{Cu}$ tem proporcionado efeitos significativos sobre a nutrição e o crescimento (REZENDE et al., 1995; SOPRANO; BRITO, 1997; BERNARDI et al., 2000). O crescimento ocorre em fluxos sucessivos de brotação da copa, sendo que a absorção dos nutrientes é maior durante as fases de desenvolvimento mais intensas do enxerto (MAUST; WILLIAMSON, 1994). Pesquisas acerca da nutrição mineral e níveis de adubação para o cultivo de variedades cítricas em recipientes são frequentes, sendo os resultados bastante variáveis de acordo com espécie cultivada, tipo de substrato, características climáticas, práticas culturais no viveiro e tipo de fertilizante aplicado (CARVALHO et al., 2000; DECARLOS NETO et al., 2002; ESPOSTI; SIQUEIRA, 2004; GIRARDI et al., 2005; SERRANO et al., 2006; BATAGLIA et al., 2008).

Entre os principais fertilizantes empregados na produção comercial de mudas de citros, destacamse os fertilizantes solúveis para fertirrigação e os de liberação controlada (GIRARDI et al., 2005). A fertirrigação é mais frequentemente adotada nos viveiros, devido à sua grande versatilidade, o que permite ajustes em cada fase fenológica da cultura, podendo ocorrer, no entanto, perdas de nutrientes por lixiviação em função de manejo incorreto da irrigação ou devido a quantidades mal dimensionadas dos fertilizantes (MILNER, 2002; BOAVENTURA et al., 2004). Já os fertilizantes de liberação controlada disponibilizam os nutrientes de forma gradual, conforme a natureza química de sua resina de recobrimento e de variáveis como umidade e temperatura do substrato, e apresentam grande praticidade na aplicação (SHAVIV, 2001). O tempo de liberação total de nutrientes pode estender-se de dois a dezoito meses, conforme a formulação e o manejo. Por outro lado, fertilizantes de liberação controlada apresentam custo unitário superior aos fertilizantes solúveis convencionalmente empregados em fertirrigação.

Há ampla oferta de fontes de fertilizantes solúveis e de liberação controlada disponíveis aos viveiristas de citros no Brasil, cuja recomendação, muitas vezes, é empírica. Este trabalho avaliou a produção de mudas de laranjeira 'Valência' sobre os porta-enxertos limoeiro 'Cravo' e citrumeleiro 'Swingle' em função de diferentes tipos de manejo da adubação recomendados por fabricantes, a partir do uso de fertilizantes solúveis e de liberação lenta aplicados isoladamente ou em associação. Objetivou- se, dessa maneira, determinar quais os manejos da adubação mais eficientes à produção de mudas cítricas protegidas dentre um elenco de estratégias disponibilizadas ao setor.

\section{MATERIAL E MÉTODOS}

O trabalho foi conduzido de setembro de 2000 a junho de 2001, em viveiro comercial de mudas cítricas localizado em Conchal-SP $\left(22^{\circ} 20^{\prime} 00^{\prime \prime} \mathrm{S}\right.$, $\left.47^{\circ} 10^{\prime} 00^{\prime \prime} \mathrm{W}, 528 \mathrm{~m}\right)$. Verificaram-se, no interior da estufa, temperaturas máximas e mínimas médias de, respectivamente, 41 e $19^{\circ} \mathrm{C}$, e umidade relativa média de $60 \%$. A cultivar copa (epibioto) estudada foi a laranjeira 'Valência' [Citrus sinensis (L.) Osbeck] e como variedades de porta-enxerto (hipobioto) avaliaram-se o limoeiro 'Cravo' (Citrus limonia Osbeck) e o citrumeleiro 'Swingle' [Citrus paradisi Macf. x Poncirus trifoliata (L.) Raf.].

Porta-enxertos de quatro meses de idade, provenientes de semeadura em tubetes $(0,075 \mathrm{~L})$, foram transplantados para sacolas plásticas $(5,0 \mathrm{~L})$, em setembro de 2000, sendo padronizados quanto à altura inicial (cerca de $18 \mathrm{~cm}$ ). A enxertia foi realizada 90 dias após a transplantação, curvandose o porta-enxerto para forçamento da brotação do enxerto. Como substrato, utilizou-se composto comercial de casca de Pinus e vermiculita (Rendmax ${ }^{\mathbb{R}}$ Citrus), que apresentou as seguintes propriedades: $\mathrm{P}$ (resina) 210,0 mg dm${ }^{-3}$; M.O. 540,0 $\mathrm{g} \mathrm{dm}^{-3} ; \mathrm{pH}$ $\left(\mathrm{CaCl}_{2}\right) 5,4 ; \mathrm{K} 1,90 ; \mathrm{Ca} 12,7 ; \mathrm{Mg} 3,2 ; \mathrm{H}+\mathrm{Al} 3,8$; T 21,50 mmol dm $\mathrm{dm}^{-3}$ V 82,8\%; S 840,0; Na 68,5; B 0,$3 ; \mathrm{Cu} 2,0 ; \mathrm{Fe} 311,5 ; \mathrm{Mn} 44,5$ e $\mathrm{Zn} 15,0 \mathrm{mg}$ $\mathrm{dm}^{-3}$ (DTPA).

Os tipos de manejos da adubação avaliados e descritos abaixo corresponderam a recomendações de fabricantes de fertilizantes, baseadas em experiências empíricas com viveiristas na época do experimento. Esses manejos resultaram em diferentes quantidades totais de nutrientes aplicados por muda em cada tratamento, durante o período avaliado (Tabela 1).

(M1): fertilizante de liberação controlada Osmocote ${ }^{\circledR} 22-04-08$, aplicado na quantidade de $2,5 \mathrm{~kg} \mathrm{~m}^{-3}$ de substrato. Essa formulação de fertilizante leva de oito a nove meses para a completa liberação dos nutrientes sob temperatura média de $21^{\circ} \mathrm{C}$ no substrato, conforme garantia do fabricante. O fertilizante foi incorporado ao substrato antes do enchimento das sacolas plásticas, conforme usualmente praticado pelo viveirista. Aproximadamente $200 \mathrm{~L}$ de substrato e $500 \mathrm{~g}$ do fertilizante foram misturados por três minutos em betoneira elétrica 
(Alfamix, Araras-SP) com capacidade de $300 \mathrm{~L}$, sem se verificarem danos aparentes aos grânulos do fertilizante.

(M2): idem M1, adicionado de termofosfato magnesiano Yoorin ${ }^{\circledR}$ Máster $\left(17,5 \% \mathrm{P}_{2} \mathrm{O}_{5} ; 20 \% \mathrm{Ca}\right.$; $9 \% \mathrm{Mg} ; 0,55 \% \mathrm{Zn} ; 0,10 \% \mathrm{~B} ; 0,05 \% \mathrm{Cu} ; 0,12 \% \mathrm{Mn}$; $0,006 \% \mathrm{Mo}$ ) na quantidade de $5,0 \mathrm{~kg} \mathrm{~m}^{-3}$ de substrato. Metade dessa quantidade foi previamente incorporada ao substrato, conforme M1, e metade aplicada manualmente em cobertura, 45 dias após a transplantação dos porta-enxertos, com 12,5 g do termofosfato por sacola plástica. A adição do termofosfato teve como objetivo elevar as concentrações de $\mathrm{P}, \mathrm{Ca}, \mathrm{Mg}$ e de micronutrientes diretamente no substrato.

(M3): idem M1, adicionado de fertilizantes solúveis da linha Peters ${ }^{\circledR}$, compondo a solução nutritiva $\left(\mathrm{mg} \mathrm{L}^{-1}\right): 6,7 \mathrm{NH}_{4}^{+} ; 93,3 \mathrm{NO}_{3}^{-} ; 120,0 \mathrm{Ca} ; 0,1$ $\mathrm{B} ; 0,05 \mathrm{Cu}$; 0,5 Fe; 0,25 Mn; 0,05 Mo; 0,33 Zn. Essa solução foi aplicada durante três períodos distintos do ciclo de produção: de 60 a 70 dias após transplantação, de 40 a 50 dias após a enxertia e de 90 a 100 dias após a enxertia. Esses três períodos corresponderam, aproximadamente, a diferentes fluxos de crescimento da parte aérea.

(M4): idem M3, contudo a fertirrigação foi aplicada diariamente após a enxertia.

(M5): fertirrigação a partir da transplantação dos porta-enxertos, com fertilizantes solúveis da linha Kristalon $^{\circledR}$, compondo a solução nutritiva $\left(\mathrm{mg} \mathrm{L}^{-1}\right)$ : 130,0 $\mathrm{NO}_{3}^{-}$; 44,0 P, 130,0 K; 105,0 Ca; 15,0 MgO; 4,0 $\mathrm{S} ; 0,1 \mathrm{~B} ; 0,04 \mathrm{Cu} ; 1,2 \mathrm{Fe} ; 0,15 \mathrm{Mn} ; 0,01 \mathrm{Mo}$; 0,1 Zn, sem adição de fertilizante de liberação controlada.

(M6): idem M5, adicionada de nitrato de cálcio e de nitrato de magnésio, nas concentrações de, respectivamente, $1,5 \mathrm{~g} \mathrm{~L}^{-1}$ e $0,5 \mathrm{~g} \mathrm{~L}^{-1}$ de solução nutritiva. A adição dos nitratos objetivou aumentar a quantidade de $\mathrm{N}, \mathrm{Ca}$ e $\mathrm{Mg}$ fornecida às plantas ao longo de todo o ciclo, respectivamente, em 280,0; 284,0; e 35,0 $\mathrm{mg} \mathrm{L}^{-1}$. Essas elevadas concentrações, embora estejam sujeitas à lixiviação, foram utilizadas com sucesso na formação de mudas cítricas de alta qualidade, em recipientes na África do Sul (MAUST; WILLIAMSON, 1994).

A irrigação foi feita diariamente via sistema de gotejamento, com lâmina de $120 \mathrm{~mL}_{\text {planta }} \mathrm{dia}^{-1}$. Nos tratamentos que empregavam a fertirrigação, praticou-se a mesma lâmina, aplicada manualmente pelo uso de béquer volumétrico. $\mathrm{O}$ volume total de água fornecido por muda, no período avaliado, foi de 32,5 L. Utilizou-se sempre a mesma fonte de água. A condutividade elétrica (CE) da água de irrigação e das soluções nutritivas para fertirrigação variou, respectivamente, de 0,01 a 0,05 e de 1,3 a $1,8 \mathrm{dS} \mathrm{m}^{-1}$. A CE e o pH da solução do substrato foram monitorados semanalmente até a enxertia, em todos os tratamentos. Para tanto, coletaramse, aleatoriamente, cinco amostras de solução do substrato, via extratores de cápsulas porosas, procedendo-se a leitura em condutivímetro digital (DIAS et al., 2005).

Os dados biométricos coletados foram: comprimento (a partir do colo da planta) e diâmetro (12 cm acima do colo da planta) do porta-enxerto, 90 dias após a transplantação; percentagem de brotação do enxerto, 60 dias após a enxertia; comprimento do enxerto, 60 e 120 dias após a enxertia; percentagem de mudas aptas à comercialização, 120 dias após a enxertia (como muda apta foi considerada aquela com copa apresentando folhas maduras completamente expandidas e comprimento de copa igual ou maior que $40 \mathrm{~cm}$ ); e massas de matéria seca da parte aérea e do sistema radicular das mudas, 180 dias após a enxertia. Neste caso, as mudas foram desplantadas e podadas na altura do colo do porta-enxerto, sendo o substrato totalmente lavado, e as duas partes obtidas foram colocadas para secagem em estufa até atingir massa constante, após $72 \mathrm{~h}$, a $64^{\circ} \mathrm{C}$.

O delineamento experimental adotado foi o fatorial 2 × 6 (porta-enxerto x manejo da adubação), em blocos casualizados, com três repetições e 12 mudas na parcela. Como a brotação do enxerto, 60 dias após a enxertia, foi inferior a 100\% em todos os tratamentos, a parcela útil para a avaliação do comprimento do enxerto, nesse período, foi de oito mudas, não se avaliando as mudas que não apresentavam brotação do enxerto. Dois meses após essa avaliação, todas as plantas haviam brotado e, portanto, as medições voltaram a ser em toda a parcela. Os dados foram submetidos às análises de variância, e as médias, comparadas pelo teste de Tukey $(P \leq$ $0,05)$. Variáveis expressas em porcentagem foram analisadas após transformação de dados do tipo arco-seno $[\sqrt{(\mathrm{x})}]$. Realizou-se também análise química de folhas dos porta-enxertos, 90 dias após a transplantação, e da variedade copa sobre ambos os porta-enxertos, 180 dias após a enxertia, com o objetivo de determinar o estado nutricional geral das plantas. Foram amostradas 30 folhas maduras e totalmente expandidas, localizadas no terço superior das plantas, compondo uma única amostra por tratamento. As amostras foram secas em estufa até atingir massa constante, após $72 \mathrm{~h}$, a $64^{\circ} \mathrm{C}$, e analisadas conforme Sarruge e Haag (1974). 


\section{RESULTADOS E DISCUSSÃO}

Conforme indicado na Tabela 1, os tipos de manejo da adubação avaliados forneceram quantidades muito variadas de nutrientes às mudas, durante o período estudado. Entre alguns tratamentos, a variação foi superior a $1.000 \%$ para um mesmo nutriente. Bernardi et al. (2000) observaram que as melhores respostas para produção de mudas de laranjeira 'Valência' sobre limoeiro 'Cravo' foram obtidas com a aplicação manual em cobertura de, respectivamente, 9,85; 2,86 e 7,99 g planta $^{-1}$ de N, P e K, num ciclo de produção de 300 dias, utilizandose de nitrato de amônio, superfosfato triplo e cloreto de potássio como fontes de nutrientes. Neste trabalho, a fertirrigação completa (M6, com aplicação de $\mathrm{N}, \mathrm{P}$ e K de, respectivamente, 9,44; 1,43 e 4,21 g) foi a que mais se aproximou daquela recomendação, de maneira que quantidades inferiores de nutrientes foram sempre fornecidas nos demais tratamentos, com exceção para o P, no M2 (4,88 g).

Bataglia et al. (2008) recomendam uma solução nutritiva genérica contendo $\left(\mathrm{mg} \mathrm{L}^{-1}\right) \mathrm{N}(200)$, P (18), K (152), Ca (140), Mg (29) e S (21) como adequada à obtenção de mudas de citros em substrato, baseando-se na análise DRIS e na composição mineral de populações de referência. A composição do substrato também deve ser considerada para ajustes dessas concentrações. Considerando-se as condições de aplicação e período estudados neste trabalho, a recomendação de Bataglia et al. (2008) resultaria em $\left(\mathrm{g} \mathrm{planta}^{-1}\right) \mathrm{N}(6,48) ; \mathrm{P}(0,58), \mathrm{K}(4,92)$, $\mathrm{Ca}(4,54), \mathrm{Mg}(0,94)$ e $\mathrm{S}(0,68)$, quantidades de nutrientes não fornecidas de maneira geral pelas recomendações de fabricantes avaliadas, exceto pelo manejo de fertirrigação completa (M6) (Tabela 1).

Não houve interação entre os portaenxertos e os diferentes manejos da adubação para nenhuma das variáveis de crescimento vegetativo estudadas, sendo que os efeitos isolados de portaenxertos e tipos de manejo são apresentados na Tabela 2. As quantidades fornecidas de nutrientes, independentemente do manejo, provavelmente não implicaram a insuficiência de quaisquer nutrientes a ambos os porta-enxertos, mas podem ter causado toxicidade ou desequilíbrios nutricionais. A análise química de folhas dos porta-enxertos e da variedade copa indicou, no entanto, suficiência de todos os nutrientes, independentemente do manejo (Tabela 3) (BATAGLIA et al., 2008). Por outro lado, diferentes comportamentos quanto à eficiência de absorção e translocação dos nutrientes em porta-enxertos de citros foram observados em trabalhos anteriores, sendo plantas de laranjeira-doce sobre limoeiro
'Cravo' mais eficientes no uso dos nutrientes em relação a plantas enxertadas sobre citrumeleiro 'Swingle', e tangerineira 'Cleópatra' (Citrus reshni Hort ex Tanaka), com 'Swingle', exigindo ainda maior aplicação de $\mathrm{N}$ e K (MATTOS JÚNIOR et al., 2006). Em cultivo protegido, condições ambientais mais adequadas ao crescimento vegetativo dos citros poderiam mitigar os efeitos dessas diferenças varietais.

Em estudo sobre a produção de subenxertos, o limoeiro ‘Cravo' apresentou crescimento mais vigoroso e acelerado após a transplantação para sacolas, em relação a Poncirus trifoliata (L.) Raf. e seus híbridos (GIRARDI et al., 2007). Entretanto, neste trabalho, plantas de citrumeleiro 'Swingle' apresentaram maiores valores de comprimento e diâmetro do caule, 90 dias após a transplantação, em relação às plantas de limoeiro 'Cravo' (Tabela 2). Essa diferença poderia ser explicada por algum desequilíbrio nutricional ou ainda por um nível de irrigação ligeiramente insuficiente para o limoeiro 'Cravo', resultando em menor crescimento, já que se adotou a mesma lâmina de água aplicada às duas espécies de porta-enxertos, e estes apresentam comportamento distinto quanto à sua demanda hídrica.

Os tipos de manejo da adubação não influenciaram nas variáveis de crescimento antes da enxertia (Tabela 2). Em trabalho similar, o emprego de fertilizantes de liberação controlada de 1,4 a 4,0 $\mathrm{kg} \mathrm{m}^{-3}$ de substrato, associado ou não a fertilizantes solúveis, também não alterou o crescimento do limoeiro 'Cravo' em recipiente de 5,0 L até o ponto de enxertia (GIRARDI et al., 2005). Contudo, trabalhos avaliando o crescimento de porta-enxertos em tubetes, da emergência até o ponto de transplantação, indicaram maiores valores de comprimento, diâmetro e matéria seca de plantas submetidas às maiores concentrações de macronutrientes (SCIVITTARO et al., 2004a,b). O emprego de fertilizantes solúveis propiciou maior diâmetro de caule de porta-enxertos de Poncirus trifoliata (L.) Raf. em tubetes, em relação a fertilizantes de liberação controlada, sob aplicação de quantidades equivalentes de $\mathrm{N}, \mathrm{P}, \mathrm{K}$ e $\mathrm{Mg}$ por muda (SCIVITTARO et al., 2004a). Por outro lado, diferentes fontes de $\mathrm{N}$ não influenciaram na altura ou diâmetro de limoeiro 'Cravo', cujo crescimento foi crescente até a concentração de $370 \mathrm{mg} \mathrm{L}^{-1}$ na solução nutritiva, independentemente do tipo de fertilizante utilizado (SCIVITTARO et al., 2004b).

A brotação do enxerto da laranjeira 'Valência' foi superior em $12,5 \%$ quando enxertada sobre limoeiro 'Cravo', 60 dias após a enxertia (Tabela 2). O emprego de termofosfato magnesiano (M2) promoveu maior brotação das borbulhas em relação à aplicação de fertilizante de liberação lenta conjugada 
à fertirrigação, durante fluxos de crescimento (M3). A influência da nutrição mineral sobre a eficiência de brotação da enxertia é pouco conhecida (HARTMANN et al., 2002), embora seu efeito positivo tenha sido observado em outras culturas, como a seringueira [Hevea brasiliensis (Willd. ex A. Juss.) Mull. Arg.] (PEREIRA et al., 1993). Em mudas dessa espécie, verificou-se maior brotação do enxerto em função de maior adubação com NPK, 15 dias antes da decepagem do porta-enxerto. Adubação similar aplicada em outras fases de formação da muda não foi eficiente.

Esse efeito não era esperado, uma vez que a adição do termofosfato magnesiano teve como objetivo principal disponibilizar maiores quantidades de $\mathrm{P}, \mathrm{Ca}, \mathrm{Mg}$ e micronutrientes para promover o crescimento do sistema radicular (REZENDE et al., 1995), sem acarretar alterações significativas no $\mathrm{pH}$ do substrato. O uso desse fertilizante também acarretou em quantidades adicionadas de micronutrientes muito superiores, em particular o boro $(27,50 \mathrm{mg}$ planta $\left.^{-1}\right)$. Embora não tenham sido observados sintomas de fitotoxidade nas mudas, as doses elevadas podem causar desequilíbrios nutricionais. Os valores de concentração foliar de nutrientes observados neste trabalho são similares aos relatados em plantas cítricas adequadamente fertilizadas, à exceção das elevadas concentrações de $\mathrm{Cu}$ em consequência da contaminação por pulverização foliar com fungicidas cúpricos efetuadas preventivamente na área experimental (Tabela 3).

Maiores valores de comprimento do enxerto foram observados em plantas sobre limoeiro 'Cravo', tanto aos 60 quanto aos 120 dias após a enxertia, sem efeito dos manejos da adubação (Tabela 2). O aproveitamento comercial, 120 DAE, também foi equivalente entre os tratamentos (60 a 70\% de mudas prontas), apesar da alta variação de crescimento das mudas. As mudas atingiram a condição de prontas 13 meses após a semeadura, dentro, portanto, do relatado por Carvalho et al. (2005) em relação ao ciclo de produção nas condições paulistas, que leva de 9 a 15 meses da semeadura à muda pronta.

Aos 180 dias após a enxertia, a massa de matéria seca do sistema radicular não diferiu entre plantas enxertadas sobre os dois porta-enxertos ou submetidas a quaisquer manejos da adubação (Tabela 2). No entanto, Girardi et al. (2005) observaram maior massa de matéria seca de sistema radicular de mudas de laranjeiras 'Valência' e 'Pera' sobre limoeiro 'Cravo', após a aplicação exclusiva de fertirrigação ou de fertilizantes de liberação controlada em baixas concentrações, em relação à aplicação de fertilizantes de liberação controlada em concentrações superiores a $3 \mathrm{~kg} \mathrm{~m}^{-3}$. As quantidades de $\mathrm{N}$, P e $\mathrm{K}$ aplicadas naqueles tratamentos foram similares ao manejo (M1) deste trabalho e, desta forma, a adição de maiores quantidades de fertilizantes não promoveu o crescimento do sistema radicular, na verdade sendo observados efeitos negativos pelo efeito salino em manejos com adubação mais intensa. Neste trabalho, a ausência de resposta em crescimento de sistema radicular pode estar relacionada à restrição de seu tamanho decorrente do uso de recipientes (OUMA, 2005), como também pelas elevadas quantidades de $\mathrm{P}, \mathrm{Fe}, \mathrm{Mn}$ e $\mathrm{Zn}$ já existentes no substrato comercial.

Houve maior acúmulo de massa de matéria seca da parte aérea em mudas enxertadas sobre o limoeiro 'Cravo' (Tabela 2), indicando o maior vigor que esse porta-enxerto induz à copa (GIRARDI; MOURÃO FILHO, 2004). O uso de fertilizante de liberação controlada adicionado de fertirrigação diária, após a enxertia (M4), levou à produção de plantas com maior massa de matéria seca, em relação àquelas manejadas com adição de termofosfato magnesiano (M2) ou fertirrigação momentânea (M3). O primeiro manejo forneceu maior quantidade de $\mathrm{N}$, especialmente a partir do crescimento do enxerto. $\mathrm{O}$ uso conjugado de fertilizantes solúveis e de liberação controlada é observado em viveiros para acelerar ou recuperar o crescimento de plantas.

$\mathrm{O}$ fornecimento de quantidades diferenciadas de nutrientes, resultando em crescimento similar das mudas cítricas, pode ser justificado por fatores como eficiência agronômica dos fertilizantes aplicados, manejo do substrato/irrigação, ou mesmo por absorção diferenciada de fontes de nutrientes pelos citros (MAUST; WILLIAMSON, 1994; BOAVENTURA et al., 2004). Desta forma, a irrigação diária pode ter promovido lixiviação dos nutrientes mesmo nos tratamentos com maiores quantidades fornecidas. A incorporação de fertilizante de liberação lenta após batimento do substrato em betoneira elétrica também não garante a total homogeneidade da mistura. Ao longo do período de avaliação, os valores de CE reduziram-se gradativamente em todos os tratamentos, enquanto os valores de $\mathrm{pH}$ se mantiveram relativamente constantes na faixa de 5,5 a 6,8 (Figura 1). Essa redução na $\mathrm{CE}$ do substrato ao longo do tempo de cultivo sugere que o manejo da irrigação foi inadequado, embora também possa demonstrar que houve absorção de nutrientes devido ao crescimento e desenvolvimento das mudas. Por fim, a estratégia de aplicação de fertilizantes em fases distintas de crescimento também não resultou em benefícios aparentes ao crescimento das mudas. 
TABELA 1 - Quantidades totais de nutrientes fornecidas às mudas de laranjeira 'Valência' enxertada em limoeiro 'Cravo' e citrumeleiro 'Swingle', da transplantação dos porta-enxertos à fase de muda pronta (270 dias), de acordo com o manejo da adubação adotado. Conchal-SP, 2001.

\begin{tabular}{|c|c|c|c|c|c|c|c|c|c|c|c|c|}
\hline Manejo $^{1}$ & $\mathrm{~N}$ & $\mathrm{P}$ & $\mathrm{K}$ & $\mathrm{Ca}$ & $\mathrm{Mg}$ & S & $\mathrm{B}$ & $\mathrm{Fe}$ & $\mathrm{Cu}$ & $\mathrm{Mn}$ & $\mathrm{Zn}$ & Mo \\
\hline & \multicolumn{7}{|c|}{---------- g planta'-1 -------- } & \multicolumn{5}{|c|}{-------- mg planta'-1 -------- } \\
\hline M1 & 2,75 & 0,50 & 1,00 & 0,00 & 0,13 & 0,38 & 2,50 & 125,00 & 6,25 & 12,50 & 6,25 & 0,13 \\
\hline M2 & 2,75 & 4,88 & 1,00 & 5,00 & 2,38 & 0,38 & 27,50 & 125,00 & 18,75 & 42,50 & 143,7 & 1,63 \\
\hline M3 & 3,11 & 0,50 & 1,00 & 0,43 & 0,13 & 0,38 & 2,86 & 126,80 & 6,43 & 13,40 & 7,44 & 0,31 \\
\hline M4 & 4,91 & 0,50 & 1,00 & 2,59 & 0,13 & 0,38 & 4,66 & 135,80 & 7,33 & 17,90 & 13,38 & 1,21 \\
\hline M5 & 4,21 & 1,43 & 4,21 & 3,40 & 0,49 & 0,13 & 3,24 & 38,88 & 1,30 & 4,86 & 3,24 & 0,32 \\
\hline M6 & 9,94 & 1,43 & 4,21 & 9,56 & 1,57 & 0,13 & 3,24 & 38,88 & 1,30 & 4,86 & 3,24 & 0,32 \\
\hline
\end{tabular}

${ }^{1}(M 1)$ = fertilizante de liberação controlada; $(M 2)=(M 1)+$ termofosfato magnesiano; $(M 3)=(M 1)+$ fertirrigação somente durante fluxos de crescimento da parte aérea; $(\mathrm{M} 4)=(\mathrm{M} 1)$ + fertirrigação diária após enxertia; (M5) = fertirrigação diária em todo o ciclo de produção; $(\mathrm{M} 6)$ = (M5) + nitratos de cálcio e de magnésio após a enxertia.

TABELA 2 - Comprimento (CPE) e diâmetro (DPE) de caule de porta-enxerto 90 dias após a transplantação (DAT), brotação da enxertia (BEX), comprimento do enxerto (CEX) 60 e 120 dias após a enxertia (DAE), massas de matéria seca da parte aérea (MPA) e do sistema radicular (MSR) 180 DAE, e aproveitamento comercial' (APC), 120 DAE, de mudas de laranjeira 'Valência' enxertadas em limoeiro 'Cravo' e citrumeleiro 'Swingle' e submetidas a diferentes manejos da adubação. Conchal-SP, 2001.

\begin{tabular}{|c|c|c|c|c|c|c|c|c|}
\hline Porta-enxerto & $\begin{array}{c}\text { CPE 90 } \\
\text { DAT } \\
(\mathrm{cm})\end{array}$ & $\begin{array}{c}\text { DPE 90 } \\
\text { DAT } \\
(\mathrm{cm}) \\
\end{array}$ & $\begin{array}{c}\text { BEX 60 } \\
\text { DAE } \\
(\%)\end{array}$ & $\begin{array}{c}\text { CEX 60 } \\
\text { DAE } \\
(\mathrm{cm})\end{array}$ & $\begin{array}{c}\text { CEX 120 } \\
\text { DAE } \\
(\mathrm{cm})\end{array}$ & $\begin{array}{c}\text { MPA 180 } \\
\text { DAE } \\
(\mathrm{g})\end{array}$ & $\begin{array}{c}\text { MSR 180 } \\
\text { DAE } \\
(\mathrm{g})\end{array}$ & $\begin{array}{c}\text { APC 120 } \\
\text { DAE } \\
(\%)\end{array}$ \\
\hline Limoeiro 'Cravo' & 113,6 & 0,50 & 91,7 & 41,0 & 66,9 & 34,1 & 37,9 & 71,3 \\
\hline $\begin{array}{l}\text { Citrumeleiro } \\
\text { 'Swingle' } \\
\end{array}$ & 117,0 & 0,57 & 81,5 & 29,5 & 53,7 & 28,4 & 34,1 & 63,9 \\
\hline D.M.S. & 2,5 & 1,2 & 6,6 & 4,4 & 6,3 & 4,0 & 4,6 & 9,8 \\
\hline C.V. $(\%)$ & 3,2 & 3,3 & 11,0 & 18,0 & 15,2 & 18,5 & 18,4 & 21,0 \\
\hline Manejo $^{2}$ & $\begin{array}{l}\text { CPE } 90 \\
\mathrm{DAT}^{3} \\
(\mathrm{~cm})\end{array}$ & $\begin{array}{c}\text { DPE } 90 \\
\text { DAT }^{3} \\
(\mathrm{~cm})\end{array}$ & $\begin{array}{c}\text { BEX } 60 \\
\text { DAE } \\
(\%)\end{array}$ & $\begin{array}{c}\text { CEX } 60 \\
\text { DAE } \\
(\mathrm{cm})\end{array}$ & $\begin{array}{c}\text { CEX } 120 \\
\text { DAE } \\
(\mathrm{cm})\end{array}$ & $\begin{array}{c}\text { MPA } 180 \\
\text { DAE } \\
(\mathrm{g})\end{array}$ & $\begin{array}{c}\text { MSR } 180 \\
\text { DAE } \\
(\mathrm{g})\end{array}$ & $\begin{array}{c}\text { APC } 120 \\
\text { DAE } \\
(\%)\end{array}$ \\
\hline$\overline{\mathrm{M} 1}$ & 111,8 & 0,54 & $86,1 \mathrm{ab}$ & 38,7 & 61,1 & $32,7 \mathrm{ab}$ & 39,6 & 68,1 \\
\hline M2 & 114,3 & 0,53 & $95,8 \mathrm{a}$ & 32,1 & 53,9 & $26,7 b$ & 30,4 & 69,4 \\
\hline M3 & 117,5 & 0,54 & $76,4 b$ & 35,7 & 61,2 & $28,6 b$ & 39,1 & 62,5 \\
\hline M4 & 116,7 & 0,53 & $93,1 \mathrm{ab}$ & 35,5 & 64,0 & $39,4 a$ & 34,8 & 71,0 \\
\hline M5 & 115,3 & 0,53 & $84,7 \mathrm{ab}$ & 36,7 & 64,9 & $30,8 \mathrm{ab}$ & 33,1 & 66,7 \\
\hline M6 & 116,1 & 0,53 & $83,3 \mathrm{ab}$ & 32,6 & 57,1 & $29,3 \mathrm{ab}$ & 38,7 & 68,1 \\
\hline D.M.S. & 6,6 & 3,2 & 17,1 & 11,4 & 16,5 & 10,4 & 11,9 & 25,5 \\
\hline C.V. $(\%)$ & 3,9 & 7,9 & 14,0 & 25,5 & 19,7 & 22,5 & 20,3 & 23,0 \\
\hline \multicolumn{9}{|l|}{ Valores de $\mathrm{F}$} \\
\hline Porta-enxerto PE) & $7,70^{*}$ & $160,86^{* *}$ & $10,34 * *$ & $30,07 * *$ & $18,58 * *$ & $8,51 * *$ & $2,86^{\mathrm{ns}}$ & $2,49^{\text {ns }}$ \\
\hline Manejo MA) & $1,82^{\mathrm{ns}}$ & $0,62^{\text {ns }}$ & $3,26^{*}$ & 0,93 ns & $1,25^{\mathrm{ns}}$ & $3,60^{*}$ & $1,92^{\mathrm{ns}}$ & $0,28^{\mathrm{ns}}$ \\
\hline$(\mathrm{PE}) \mathrm{x}(\mathrm{MA})$ & $2,64^{\mathrm{ns}}$ & $1,38^{\mathrm{ns}}$ & $1,73^{\mathrm{ns}}$ & $2,47^{\mathrm{ns}}$ & $2,21^{\mathrm{ns}}$ & $0,62^{\mathrm{ns}}$ & $1,09^{\mathrm{ns}}$ & $0,69^{\mathrm{ns}}$ \\
\hline
\end{tabular}

*,**, ns Valores de teste $\mathrm{F}$, respectivamente significativos a $5 \%$ e $1 \%$ de probabilidade, e não significativos. Médias seguidas por letras diferentes em colunas diferem entre si, pelo teste de Tukey $(P \leq 0,05)$.

${ }^{1}$ Corresponde à percentagem de mudas aptas à comercialização, ou seja, com copa apresentando folhas maduras completamente expandidas e comprimento de enxerto igual ou maior que $40 \mathrm{~cm}$.

${ }^{2}(M 1)=$ fertilizante de liberação controlada; $(M 2)=(M 1)+$ termofosfato magnesiano; $(M 3)=(M 1)+$ fertirrigação somente durante fluxos de crescimento da parte aérea; $(M 4)=(M 1)$ + fertirrigação diária após enxertia; (M5) = fertirrigação diária em todo o ciclo de produção; $(\mathrm{M} 6)=(\mathrm{M} 5)$ + nitratos de cálcio e de magnésio após a enxertia.

${ }^{3}$ Valores referentes a ambos os porta-enxertos. 
TABELA 3 - Concentração foliar de macro e micronutrientes em plantas de limoeiro 'Cravo' e citrumeleiro 'Swingle', 90 dias após o transplante, e laranjeira 'Valência' sobre ambos os porta-enxertos, 180 dias após a enxertia, e submetidas a diferentes manejos nutricionais no viveiro. ConchalSP, 2001.

\begin{tabular}{|c|c|c|c|c|c|c|c|c|c|c|c|c|}
\hline \multirow[t]{2}{*}{ Espécie } & \multirow[t]{2}{*}{ Manejo $^{1}$} & \multicolumn{11}{|c|}{ Concentração foliar } \\
\hline & & $\mathrm{N}$ & $\mathrm{P}$ & K & $\mathrm{Ca}$ & $\mathrm{Mg}$ & $\mathrm{S}$ & B & $\mathrm{Cu}$ & $\mathrm{Fe}$ & $\mathrm{Mn}$ & $\mathrm{Zn}$ \\
\hline & & --- & 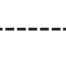 & -- & $\gamma \sigma^{-1}$ & & & ----- & ----- & $\alpha^{-1}$ & & \\
\hline \multirow{7}{*}{$\begin{array}{l}\text { Limoeiro } \\
\text { 'Cravo' }\end{array}$} & M1 & 32,5 & 1,7 & 20,7 & 13,3 & 2,3 & 2,4 & 28 & 164 & 96 & 20 & 20 \\
\hline & M2 & 27,0 & 1,8 & 20,1 & 13,1 & 2,7 & 2,6 & 59 & 175 & 88 & 19 & 28 \\
\hline & M3 & 31,6 & 1,5 & 19,6 & 13,3 & 2,4 & 2,4 & 24 & 163 & 87 & 19 & 19 \\
\hline & M4 & 29,7 & 1,7 & 21,1 & 15,4 & 2,5 & 2,7 & 31 & 147 & 87 & 20 & 21 \\
\hline & M5 & 28,6 & 2,0 & 25,8 & 15,2 & 2,2 & 3,0 & 31 & 249 & 122 & 18 & 21 \\
\hline & M6 & 29,4 & 1,6 & 22,7 & 14,4 & 2,3 & 2,9 & 31 & 181 & 246 & 19 & 22 \\
\hline & Média & 29,8 & 1,7 & 21,7 & 14,1 & 2,4 & 2,7 & 34 & 180 & 121 & 19 & 22 \\
\hline \multirow{7}{*}{$\begin{array}{l}\text { Citrumeleiro } \\
\text { 'Swingle' }\end{array}$} & M1 & 33,2 & 2,1 & 19,3 & 19,4 & 4,8 & 2,6 & 31 & 371 & 120 & 29 & 25 \\
\hline & M2 & 32,5 & 2,0 & 20,1 & 19,8 & 4,9 & 2,6 & 54 & 245 & 102 & 23 & 29 \\
\hline & M3 & 31,9 & 2,1 & 19,1 & 24,0 & 5,0 & 2,7 & 32 & 357 & 110 & 29 & 25 \\
\hline & M4 & 32,6 & 2,1 & 18,8 & 20,1 & 4,8 & 2,7 & 30 & 295 & 129 & 27 & 26 \\
\hline & M5 & 31,1 & 2,0 & 22,0 & 17,5 & 4,6 & 2,7 & 33 & 359 & 133 & 19 & 18 \\
\hline & M6 & 32,2 & 1,8 & 22,6 & 20,3 & 4,1 & 2,5 & 31 & 434 & 116 & 17 & 18 \\
\hline & Média & 32,3 & 2,0 & 20,3 & 20,2 & 4,7 & 2,6 & 35 & 344 & 118 & 24 & 24 \\
\hline \multirow{7}{*}{$\begin{array}{l}\text { Laranjeira } \\
\text { 'Valência' } \\
\text { sobre limoeiro } \\
\text { 'Cravo' }\end{array}$} & M1 & 28,0 & 1,8 & 29,9 & 17,6 & 2,8 & 2,2 & 39 & 3887 & 188 & 32 & 39 \\
\hline & M2 & 29,8 & 1,8 & 29,7 & 17,8 & 2,9 & 2,3 & 94 & 3990 & 145 & 26 & 45 \\
\hline & M3 & 29,4 & 2,0 & 30,4 & 16,6 & 2,9 & 2,1 & 42 & 3599 & 142 & 32 & 35 \\
\hline & M4 & 31,4 & 1,6 & 27,8 & 22,8 & 3,0 & 2,8 & 36 & 2907 & 148 & 45 & 34 \\
\hline & M5 & 32,6 & 1,3 & 33,0 & 20,0 & 2,8 & 2,6 & 37 & 3116 & 124 & 28 & 34 \\
\hline & M6 & 30,8 & 1,4 & 28,0 & 22,4 & 2,8 & 2,1 & 34 & 3877 & 144 & 35 & 37 \\
\hline & Média & 30,3 & 1,7 & 29,8 & 19,5 & 2,9 & 2,4 & 47 & 3563 & 149 & 33 & 37 \\
\hline \multirow{7}{*}{$\begin{array}{l}\text { Laranjeira 'Va- } \\
\text { lência' sobre } \\
\text { citrumeleiro } \\
\text { 'Swingle' }\end{array}$} & M1 & 31,8 & 2,2 & 26,7 & 19,0 & 3,8 & 2,4 & 52 & 3971 & 120 & 21 & 36 \\
\hline & M2 & 32,6 & 2,2 & 26,5 & 20,2 & 3,9 & 2,0 & 92 & 3819 & 121 & 15 & 40 \\
\hline & M3 & 30,6 & 2,0 & 25,0 & 20,0 & 3,8 & 3,2 & 58 & 4218 & 132 & 21 & 38 \\
\hline & M4 & 34,2 & 1,9 & 24,8 & 26,8 & 3,8 & 3,5 & 47 & 3705 & 117 & 32 & 33 \\
\hline & M5 & 33,2 & 1,9 & 29,1 & 22,2 & 3,7 & 3,0 & 44 & 3498 & 116 & 24 & 30 \\
\hline & M6 & 34,5 & 1,8 & 28,2 & 24,8 & 3,6 & 2,7 & 45 & 4142 & 126 & 26 & 34 \\
\hline & Média & 32,8 & 2,0 & 26,7 & 22,2 & 3,8 & 2,8 & 56 & 3892 & 122 & 23 & 35 \\
\hline
\end{tabular}

${ }^{1}(\mathrm{M} 1)$ = fertilizante de liberação controlada; $(\mathrm{M} 2)=(\mathrm{M} 1)$ + termofosfato magnesiano; $(\mathrm{M} 3)=(\mathrm{M} 1)$ + fertirrigação somente durante fluxos de crescimento da parte aérea; $(\mathrm{M} 4)=(\mathrm{M} 1)$ + fertirrigação diária após enxertia; (M5) = fertirrigação diária em todo o ciclo de produção; (M6) = (M5) + nitratos de cálcio e de magnésio após a enxertia. 


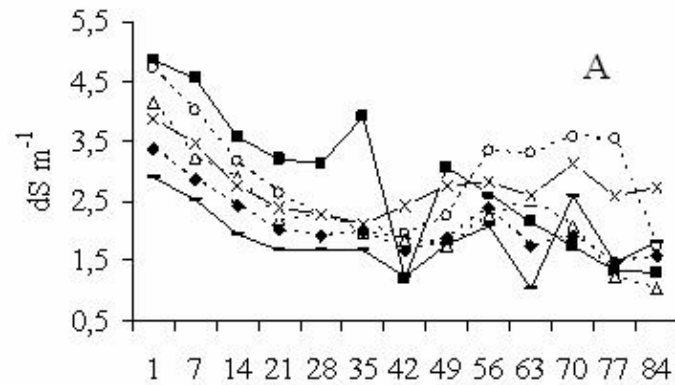

Dias após a transplantação

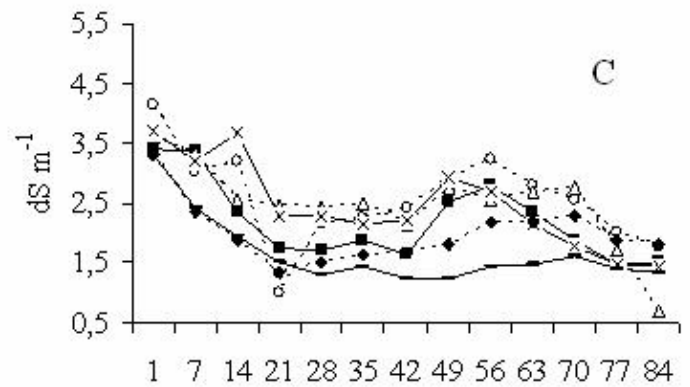

Dias após a transplantação

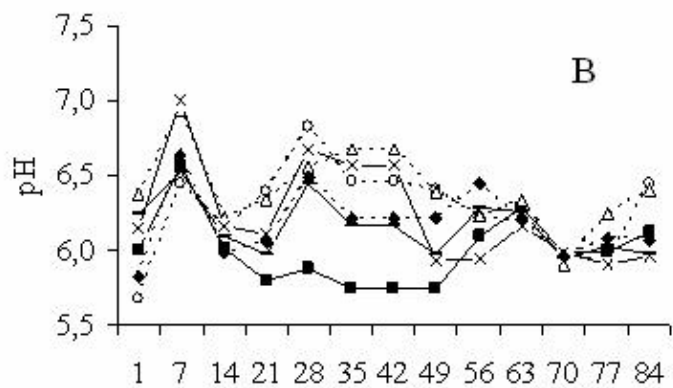

Dias após a transplantação

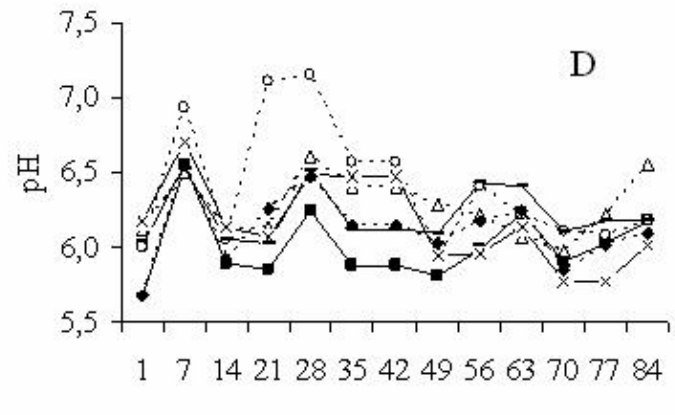

Dias após a transplantação

$(\mathrm{M} 1)=$ fertilizante de liberação controlada; $(\mathrm{M} 2)=(\mathrm{M} 1)+$ termofosfato magnesiano; $(\mathrm{M} 3)=(\mathrm{M} 1)$ + fertirrigação somente durante fluxos de crescimento da parte aérea; $(\mathrm{M} 4)=(\mathrm{M} 1)+$ fertirrigação diária após enxertia; $(\mathrm{M} 5)$ = fertirrigação diária em todo o ciclo de produção; $(\mathrm{M} 6)=(\mathrm{M} 5)+$ nitratos de cálcio e de magnésio após a enxertia.

FIGURA 1 - Variação semanal de condutividade elétrica (A e C) e pH (B e D) do substrato de cultivo de laranjeira 'Valência' enxertada sobre limoeiro 'Cravo' (A e B) e citrumeleiro 'Swingle' (C e D), submetidos a diferentes manejos nutricionais no viveiro, até a enxertia, entre 1 e 84 dias após a transplantação. Conchal-SP, $2001(\mathrm{n}=5)$.

\section{CONCLUSÕES}

Nas condições em que foi realizado o trabalho, o manejo da adubação representado pelo uso exclusivo de fertilizante de liberação controlada 2204-08, na concentração de $2,5 \mathrm{~kg} \mathrm{~m}^{-3}$, é indicado à adequada formação de mudas de laranjeira 'Valência' em recipientes. Esse manejo acarretou tanto nas menores quantidades totais de nutrientes aplicadas no período de avaliação, como em elevado crescimento vegetativo e aproveitamento comercial das mudas, nove meses após a transplantação em sacolas.

\section{AGRADECIMENTOS}

Às empresas Citrograf Mudas, Yara Brasil Fertilizantes S.A. e The Scotts Company, pelo apoio técnico e fornecimento dos materiais utilizados neste experimento; a Dra. Sônia Maria de Stefano Piedade (ESALQ/USP), pelas sugestões quanto à análise estatística. 


\section{REFERÊNCIAS}

BATAGLIA, O.C.; FURLANI, P.R.; FERRAREZI, R.S.; MEDINA, C.L. Padrão nutricional de mudas de citros. Araraquara: Vivecitrus, 2008. 40p.

BERNARDI, A.C.C.; CARMELLO, Q.A.C.; CARVALHO, S.A. Development of citrus nursery trees grown in pots in response to NPK fertilization. Scientia Agricola, Piracicaba, v.57, n.4, p.733-738, 2000 .

BOAVENTURA, P.S.; QUAGGIO, J.A.; ABREU, M.F.; BATAGLIA, O.C. Balanço de nutrientes na produção de mudas cítricas cultivadas em substrato. Revista Brasileira de Fruticultura, Jaboticabal, v.26, n.2, p.300-305, 2004.

CARVALHO, S.A. DE; GRAF, C.C.D.; VIOLANTE, A.R. Produção de material básico e propagação. In: MATTOS JUNIOR, D.; NEGRI, J.D. de; PIO, R.M.; POMPEU JUNIOR, P. Citros. Campinas: Instituto Agronômico, 2005. p.281-316.

CARVALHO, S.A.; MATTOS JUNIOR, D.; SOUZA, M. Efeito do $\mathrm{KNO}_{3}$ nos teores de macronutrientes na matéria seca total de porta-enxertos cítricos produzidos em bandejas. Bragantia, Campinas, v.59, n.1, p.89-94, 2000.

DECARLOS NETO, A.; SIQUEIRA, D.L.; PEREIRA, P.R.G.; ALVAREZ, V.H. Diagnóstico do estado nutricional de $\mathrm{N}$ em porta-enxertos de citros, utilizando-se de teores foliares de clorofila. Revista Brasileira de Fruticultura, Jaboticabal, v.24, n.1, p.204-207, 2002.

DIAS, N.S.; DUARTE, S.N.; GHEYI, H.R.; MEDEIROS, J.F.; SOARES, T.M. Manejo da fertirrigação e controle da salinidade do solo sob ambiente protegido, utilizando-se de extratores de solução do solo. Revista Brasileira de Engenharia Agrícola e Ambiental, Campina Grande, v.9, n.4, p.496-504, 2005.

ESPOSTI, M.D.D.; SIQUEIRA, D.L. Doses de ureia no crescimento de porta-enxertos de citros produzidos em recipientes. Revista Brasileira de Fruticultura, Jaboticabal, v.26, n.1, p.136-139, 2004.
GIRARDI, E.A.; MOURÃO FILHO, F.A.A. Crescimento inicial de laranjeira 'Valência' sobre dois porta-enxertos em função da adubação nitrogenada no plantio. Revista Brasileira de Fruticultura, Jaboticabal, v.26, n.1, p.117-119, 2004.

GIRARDI, E.A.; MOURÃO FILHO, F.A.A.; GRAF, C.C.D.; OLIC, F.B. Influence of soluble and slow-release fertilizers on vegetative growth of containerized citrus nursery trees. Journal of Plant Nutrition, Philadelphia, v.28, n.9, p.1465-1480, 2005.

GIRARDI, E.A.; MOURÃO FILHO, F.A.A.; PIEDADE, S.M.S. Desenvolvimento vegetativo e custo de produção de porta-enxertos de citros em recipientes para fins de subenxertia. Pesquisa Agropecuária Brasileira, Brasília, v.42, n.5, p.679687, 2007.

HARTMANN, H.T.; KESTER, D.E.; DAVIES JUNIOR., F.T.; GENEVE, R.L. Plant propagation: principles and practices. 7. ed. New Jersey: Prentice Hall, 2002. 880p.

MATTOS JUNIOR, D.; QUAGGIO, J.A.; CANTARELLA, H.; ALVA, A.K.; GRAETZ, D. A. Response of young citrus trees on selected rootstocks to nitrogen, phosphorus, and potassium fertilization. Journal of Plant Nutrition, Philadelphia, v.29, n.8, p.1371-1385, 2006.

MAUST, B.E.; WILLIAMSON, J.G. Nitrogen nutrition of containerized citrus nursery plants. Journal of American Society for Horticultural Science, Alexandria, v.119, n.2, p.195-201, 1994.

MILNER, L. Manejo de irrigação e fertirrigação em substratos. In: FURLANI, A.M.C.; BATAGLIA, O.C.; ABREU, C.A.; FURLANI, P.R.; QUAGGIO, J.A.; MINAMI, K. Caracterização, manejo e qualidade de substratos para produção de plantas. Campinas: Instituto Agronômico, 2002. p.45-51.( Documentos, 70).

OUMA, G. Root confinement and irrigation frequency affect growth of rough lemon (Citrus limon) seedlings. Fruits, Montpellier, v.60, n.3, p.195-202, 2005. 
PEREIRA, J.P.; LUCCHESI, A.A.; SILVEIRA, R.I. Adubação da seringueira no período de pós-enxertia. I: Relacionada à data de decepagem do porta-enxerto. Scientia Agricola, Piracicaba, v.50, n.2, p.204-211, 1993.

REZENDE, L. P.; AMARAL, A.M.; CARVALHO, S.A.; SOUZA, M. Volume de substrato e superfosfato simples na formação do limoeiro 'Cravo' em vasos. I. Efeitos no crescimento vegetativo. Revista Laranja, Cordeirópolis, v.16, n.2, p.165-177, 1995.

SARRUGE, J.R.; HAAG, H.P. Análises químicas em plantas. Piracicaba: ESALQ/USP, 1974. 54p.

SCIVITTARO, W.B.; OLIVEIRA, R.P.; MORALES, C.F.G.; RADMANN E.B. Adubação nitrogenada na formação de porta-enxertos de limoeiro Cravo em tubetes. Revista Brasileira de Fruticultura, Jaboticabal, v.26, n.1, p.131-135, 2004b.
SCIVITTARO, W.B.; OLIVEIRA, R.P.; RADMANN, E.B. Doses de fertilizantes de liberação lenta na formação do porta-enxerto 'Trifoliata'. Revista Brasileira de Fruticultura, Jaboticabal, v.26, n.3, p.520-523, 2004a.

SERRANO, L.A.L.; MARINHO, C.S.; BARROSO, D.G.; CARVALHO, A.J.C. Sistemas de blocos prensados e doses de adubo de liberação lenta na formação de porta-enxerto cítrico. Ciência Rural, Santa Maria, v.36, n.2, p.441-447, 2006.

SHAVIV, A. Advances in controlled-release fertilizers. Advances in Agronomy, San Diego, v.71, p.1-49, 2001.

SOPRANO, E.; BRITO, C.J.F.A. Caracterização de deficiências nutricionais em mudas cítricas. Itajaí: EPAGRI, 1997. (Boletim Técnico). 